\title{
Prof. William Jones and his Materials Chemistry Group: Innovations and Advances in the Chemistry of Solids
}

\author{
Dejan-Krešimir Bučar ${ }^{\dagger} *$ and Tomislav Friščić ${ }^{\dagger} *$ \\ ${ }^{\dagger}$ Department of Chemistry, University College London, 20 Gordon Street, London WC1H 0AJ, United Kingdom \\ *Department of Chemistry, McGill University, 801 Sherbrooke Street W., Montreal, Quebec H3A 0B8, Canada
}

This Virtual Special Issue celebrates the beginning of a new chapter in the career of William (Bill) Jones, now Emeritus Professor at the Department of Chemistry at the University of Cambridge. The collection of papers in this issue also marks the profound influence he has had on the development of new concepts in materials science, organic solid-state chemistry and crystal engineering. Last but not least, this issue is a testament to the tremendous support and inspiration he has provided to numerous colleagues, collaborators, students and postdoctoral researchers throughout his career.

Bill was born in Mold (Wales, UK) in 1949. He obtained a BSc (Hons) from the University College of Wales (Aberystwyth, UK) in 1971. He then pursued a $\mathrm{PhD}$ degree at the same institution, under the guidance of Professor Sir John Meurig Thomas and Professor John O. Williams. After being awarded his Phd in 1974, he completed a postdoctoral fellowship at the Weizmann Institute (Rehovot, Israel; 1975-76), then moved to the University of Cambridge (Cambridge, UK; 1978). It was a there that he later established his Materials Chemistry Group. Bill eventually became the Head of the Department of Chemistry at Cambridge, and the Deputy Director of the Pfizer Institute of Pharmaceutical Materials Sciences. Bill has also been a Visiting Professor at State University of New York (New York, USA, 1988) and at McGill University (Montreal, Canada, 2012), and an Adjunct Professor at the World Premier Institute (Japan, 2010-2015). His contributions to the solid-state sciences have won him many accolades throughout his career, including a Jacob London Fellowship (which he took to the Weizmann Institute) and the Royal Society of Chemistry Corday Morgan Prize (awarded for the most meritorious contributions to experimental chemistry). He is the acting president of the British Association for Crystal Growth, and an Emeritus Professorial Fellow at Sidney Sussex College (at the University of Cambridge).

Bill's research career encompassed several areas of organic solid-state chemistry, crystal engineering and materials science, but was primarily focused on the use of transmission electron microscopy and atomic force

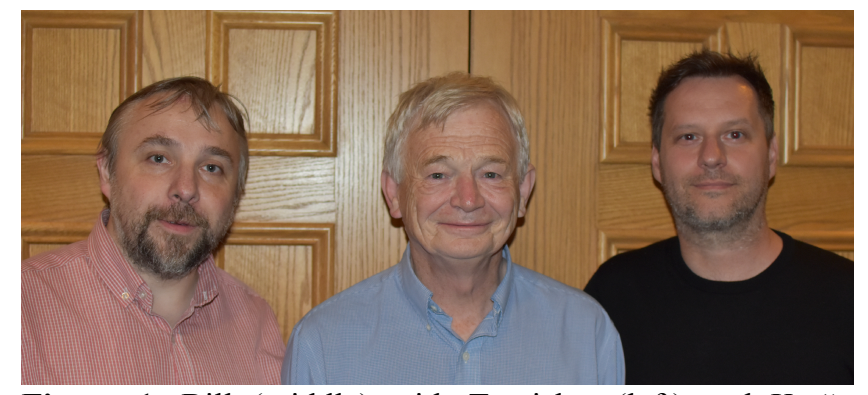

Figure 1. Bill (middle) with Tomislav (left) and Krešo (right) at the 2016 Crystal Engineering Gordon Research Conference in Stowe, VT, USA. Credit: Prof. Sally Price.

microscopy to study crystal defects and phase transformations, organic solid-state photochemistry, the development of crystal design strategies and the application of mechanochemistry to the discovery of pharmaceutical crystal forms. Bill has always espoused a crossdisciplinary and collaborative approach to solid-state research, often strengthened by the unconventional use of the latest analytical techniques (e.g., terahertz spectroscopy, transmission-electron and atom-force microscopy), computational tools (e.g., crystal structure prediction) and innovative synthetic methods (e.g., liquidassisted grinding, previously known as solvent-drop grinding). In the next few sections, we reflect on his long fruitful scientific career and his many outstanding contributions to organic-solid-state chemistry and crystal engineering.

\footnotetext{
Applications of transmission-electron and atom-force microscopy in (organic) solid-state chemistry and materials science

In the 1970s, Bill launched a series of studies focusing on the on the characterization of defects in molecular crystals and electron-beam induced changes to crystals and their molecular constituents; these experiments were guided by his expertise in the electron microscopy of beam-sensitive materials. An early and particularly striking study described the structural characterization of a low-temperature polymorph of pyrene. ${ }^{1}$
} 

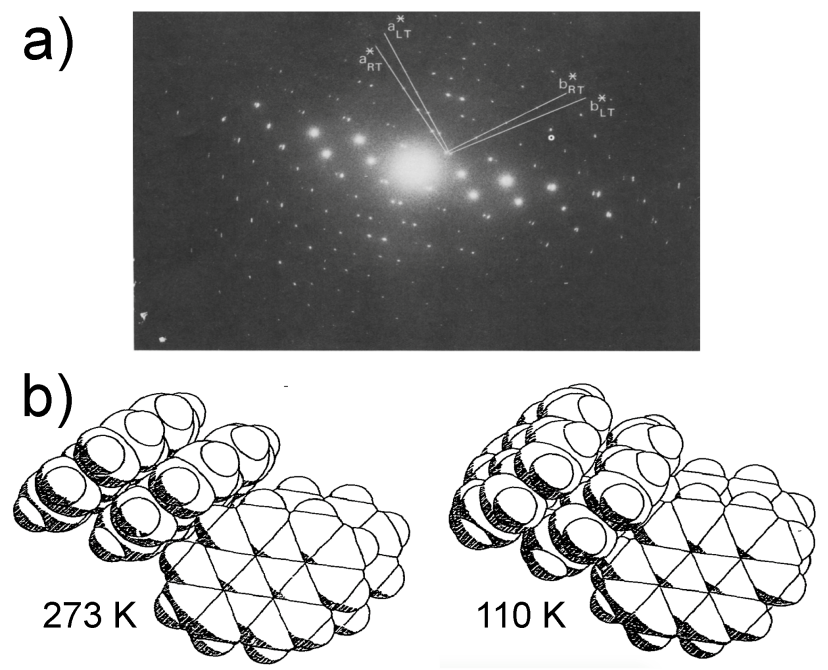

Figure 2. a) Electron diffraction pattern, used to determine the structure of the low temperature polymorph of pyrene. The pattern was collected at $110 \mathrm{~K}$, and displays diffraction peaks for both the room- and low-temperature polymorphs. b) Packing diagrams of the room- and lowtemperature polymorphs. Panels (a) and (b) are adapted with permission from ref 1. Copyright 1978 Elsevier.

Pyrene undergoes a phase transition that is accompanied by a change in its luminescent properties. Since crystal shattering precluded single-crystal X-ray diffraction studies in 1977, Bill resorted to using electron diffraction studies in combination with atom-atom potential calculations. This approach ultimately led to the determination of the crystal structure of the low-temperature polymorph (Figure 2), and the unorthodox combination of diffraction and computational methods later became a standard Materials Chemistry Group protocol for the structural characterization of solids in the absence of single-crystals. ${ }^{2-5}$ This protocol is now being widely implemented by crystal engineers and organic solid-state chemists. In recent years, Bill and his coworkers have also led the way in the identification of polymorphs using atomic-force microscopy ${ }^{6}$ height images to distinguish polymorphs of molecular crystals. ${ }^{7}$

\section{Solid-state photoreactivity, single-crystal-to-single- crystal transformations and crystal design principles}

Bill was a post-doctoral fellow at the Weizmann Institute at a time when it was a renowned center of excellence in the field of organic solid-state photochemistry. Influenced by his time there, he extended his microscopy studies to investigate crystal defects in photoreactive molecular solids (such as anthracenes, divinylbenzenes and styrylpyrazines ${ }^{8}$ ), in an effort to determine how crystal dislocations affect the regioselectivity and other aspects of their solid-state reactivity. In this context, he made use of transmission electron microscopy (capable of examining surface areas of $10 \times 10 \mu \mathrm{m}^{2}$ ) to assess the conversion rates of monomers to polymers within crystals, as well as to gain insight into the role of structural defects in the progression of solid-state photodimerisa- tion reactions, ${ }^{8}$ and to explain the formation of unexpected photoproducts (such as the trans photodimer of 9-cyanoanthracene, which forms crystals wherein the monomers are stacked in a cis fashion). ${ }^{9-10}$

Building on pioneering works by Kohlschütter and Schmidt, Bill and his collaborators were also directing their attention to crystallographic aspects of the solidsate photodimerisation reactions of benzylbenzylidenecyclopentanones (BBCPs). Their main subjects were BBCPs with unsubstituted and bromo-substituted phenyl groups, as well as $\mathrm{Cl}$ - and $\mathrm{CH}_{3}$-substituted benzyl sites ${ }^{11}$; this family of compounds became the basis of a systematic exploration of topotactic and topochemical photoreactions, with a particular focus on the manner in which molecular substitutions affect their reactivity. Such crystallographic studies resulted in several pivotal accomplishments: For example, the introduction of single-crystal X-ray diffraction as a tool to study dynamic changes in photoreactive solids led to the structural characterization of the first single-crystal-to-singlecrystal (SCSC) transformations based on a [2+2] photodimerisation reaction (Figure 3). ${ }^{12-14}$ These results, obtained from unreacted, partially reacted and full reacted single crystals, revealed that the [2+2] photodimerization reactions can only be described using complex structural models, which take into account the gradual change in concentration of dimers from the crystal surface (highest concentration) to the core of the crystal (lowest concentration). It was also proposed that, in the absence of a phase separation of the dimers, it is feasible to expect the existence of an range of "molecular orientations intermediate between those of the monomer and dimer since these are likely to depend on the exact local environment." ${ }^{\text {14 }}$ Later, the group also studied photoinduced SCSC transformations in crystals of diacetylenes ${ }^{15,16}$ and acridizinium salts. ${ }^{17-19}$

Following Kitaigorodskii's pioneering studies of solidstate solubility and isomorphism in molecular crystals ${ }^{20}$, and prompted by the discovery of isomorphous crystals in the BBCP family ${ }^{11}$, Jones and co-workers explored the use of functional-group interchangeability principles to engineer solid-state cross-photodimerization reactions. In a landmark crystal-engineering study in organic solid-state photochemistry, ${ }^{21}$ Jones and Desiraju accomplished the cross-photodimerization of various $\mathrm{Cl}$ - and $\mathrm{CH}_{3}$ derivatives of BBCPs in their solid solutions. A particularly impressive feat was the crossphotodimerization of two non-isostructural Br-BBCPs, one of which was known to be photostable in the solid state as a consequence of its unfavorable molecular conformation in the solid state. By taking advantage of the $\mathrm{Cl} / \mathrm{CH}_{3}$ exchange rule, and the ability of the photostable $\mathrm{Br}-\mathrm{BBCP}$ to mimic the conformation of the photoactive counterpart, ${ }^{22}$ the photostable Br-BBCP was successfully introduced into the matrix (i.e., crystal lattice) of the photoactive Br-BBCP to yield both homodimers and the heterodimer upon UV irradiation. The Materials 
a)

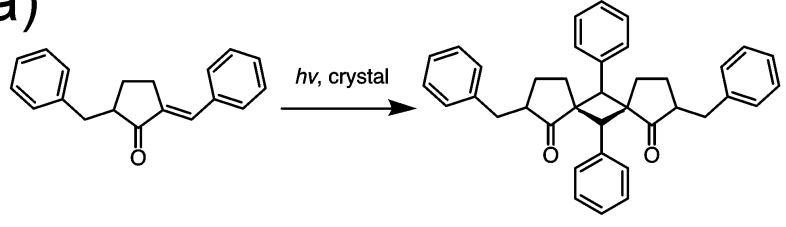

b)

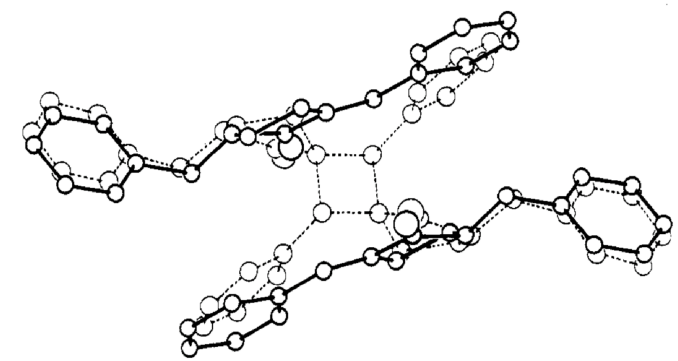

C)
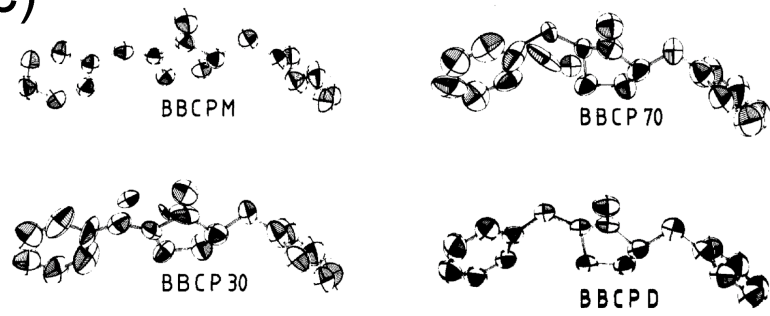

Figure 3. a) Photodimerization of BBCP b) a composite figure showing the relative orientation of the $\mathrm{BBCP}$ monomer and dimer in a UV-irradiated single crystal of $\mathrm{BBCP}$ and c) ORTEP plots showing a photodimerizing BBCP monomer at $0 \%, 30 \%, 70 \%$ and $100 \%$ yield. Panels (b) and (c) are adapted with permission from ref 14. Copyright 1981 American Chemical Society.

Chemistry Group also studied cross-photodimerization reactions involving compounds based on interchangeable benzene, pyridyl and pyrazyl moieties. ${ }^{23}$

The Materials Chemistry Group maintained its interest in Kitaigorodskii's interchangeability principles beyond the study of photoactive materials, and also investigated their applicability to the design of multi-component molecular cocrystals, leading to one of the first systematic analyses - based on both crystallographic data and surveys of the Cambridge Structural Database ${ }^{24-25}$ - of the $\mathrm{Cl} / \mathrm{CH}_{3}$ interchangeability in cocrystals. Not surprisingly, their conclusions were consistent with earlier observations that the $\mathrm{Cl} / \mathrm{CH}_{3}$ exchange principle is not likely to apply in cases where a replaced $\mathrm{Cl}$ atom is involved in directional electrostatic interactions. ${ }^{26}$ This work had an additional, important effect on the broader community: it encouraged the examination of other functional groups deemed to be exchangeable in the organic solid state.

Subsequent work by Jones, Friščić and Cinčić led to the establishment of the supramolecular equivalence of two halogen-bond donors (namely, $\mathrm{Br}$ and $\mathrm{I})^{27-28}$ and three acceptors (namely, $\mathrm{O}, \mathrm{N}-\mathrm{H}$ and $\mathrm{S})^{28}$ in a series of halogen-bonded cocrystals. These studies and their findings are highly relevant, as they signify that
Kitaigorodskii's exchange principles might only apply under specific conditions, and that a successful exchange of functional groups strongly depends on the environment of the exchanged moiety, as well as on the nature of the intermolecular interaction that this group is engaged in. ${ }^{29-30}$

Bill's group has also contributed to our better understanding of molecular solids included through some the earliest studies of synthon hierarchies in molecular cocrystals. For example, Shan, Batchelor and Jones reported a $\mathrm{R}_{2}{ }^{2}(7) v s . \mathrm{R}_{2}^{2}(8)$ "synthon competition"31 study using a series of cocrystals composed of 4,7phenanthroline and a carboxylic acid. Phenanthroline was selected as probe as due to the local environments of each $\mathrm{sp}^{2}$-hybridized nitrogen atom, providing the opportunity to form either an $R_{2}^{2}(7)$ or an $R_{2}^{2}(8)$ synthon involving a pair of $\mathrm{O}-\mathrm{H} \cdots \mathrm{N}$ and a $\mathrm{C}-\mathrm{H} \cdots \mathrm{O}$ interactions. Crystallographic studies established in all cases the exclusive formation of $\mathrm{a}_{2}^{2}(7)$ synthon, indicating their greater stability, as compared a $\mathrm{R}_{2}{ }^{2}(8)$ interaction (Figure 4). This little-known study, simple and yet convincing, shines as an example of an elegant and effective strategy to probe molecular self-assembly in solids.
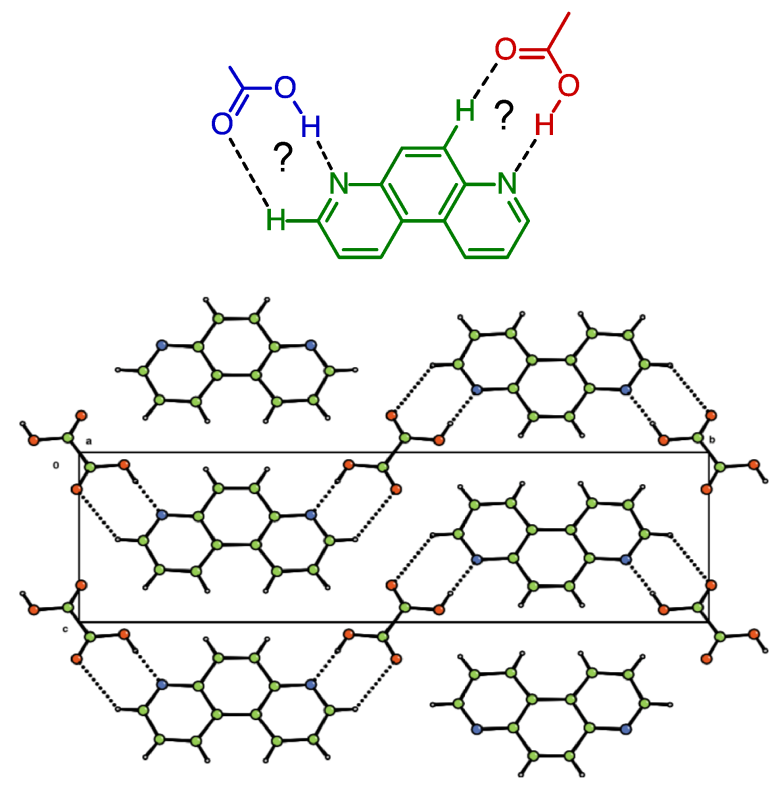

Figure 4. Competition of $R_{2}^{2}(7)$ vs $R_{2}^{2}(8)$ synthons in a cocrystal composed of 4,7-phenantroline and carboxylic acid (top) and the crystal structure of the (4,7phenanthroline).(oxalic acid) cocrystal featuring $R_{2}^{2}(7)$ synthons (bottom). Adapted with permission from ref 31 . Copyright 2002 Elsevier.

\section{Inorganic side of the Materials Chemistry Group: mes- oporous silicas, zeolites, clays and salts}

Besides organic solids, a major focus of Bill's Materials Chemistry Group have been different classes of inorganic materials, and in particular layered solids such as layered double hydroxide (LDH) materials, framework solids (such as zeolites), and complex salts (for example 


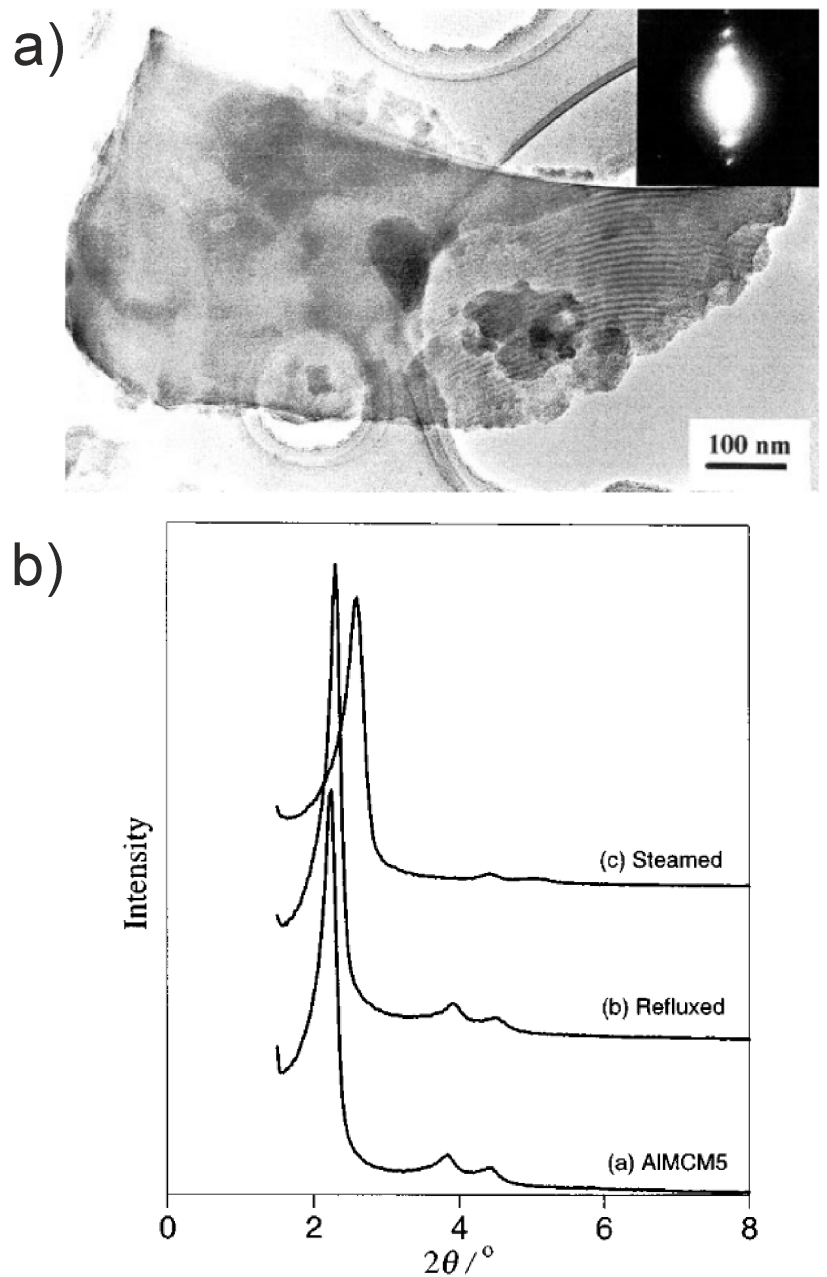

Figure 5. a) Transmission electron microscopy image and corresponding selected area electron diffraction pattern of a large crystal of MCM-41 and PXRD patterns of aluminium-grafted sample of MCM-41 compared to the sample after 4 hours steaming at $750{ }^{\circ} \mathrm{C}$ and 16 hours in boiling water, demonstrating structural stability. Panels (a) were adapted with permission from refs 32 and 33. Copyright 1998 and 1999 Royal Society of Chemistry.

different "perhydrates"; solid forms of hydrogen peroxide). Indeed, the width of Bill's research interests and its persistent focus on understanding and learning how to control the structure and therefore the functionality of materials (rather than on following artificial divisions between inorganic, organic or metal-organic solids) is very well illustrated by his work on solid-state structures and structural changes in reactions of solid peroxides. Whereas this work has led to structural characterization of organic solids, for example peroxycarboxylic acids, ${ }^{34-}$ 35 it has also included the exploration of metal-organic materials, for example magnesium peroxyphthalate, ${ }^{36}$ an important oxidation and epoxidation reagent in organic synthesis. On the opposite side of spectrum, Cosgrove and Jones ${ }^{37-39}$ have provided a series of papers outlining the detailed analysis of the reactivity, structural understanding and, eventually advances in the design of a particularly complex family of multi-components solids - the alkaline metal sulfate chlorides perhydrates.

Zeolites, clays and other related framework and layered materials are ubiquitous in modern industry and technology, manufactured in millions of tons annually and comprising markets worth many tens of billions US dollars per year. In this area also, Bill's group has left a permanent mark through their work on the modification and crystallization of zeolites. Notably, the Jones Materials Chemistry Group in Cambridge was finding new ways to crystallize, use and modify advanced silica materials, such as MCM-41, very quickly after they were first reported. An example of such work is "A method for the synthesis of high quality large crystal MCM-41,32 developed by Mokaya, Zhou and Jones, who used seeding of solutions with "primary MCM-41" crystals to obtain "secondary MCM-41" crystals that were over an order of magnitude larger, almost micrometer-sized, and of improved quality evidenced by selected area electron diffraction patterns (Figure 5a).

There have been a number of advances that the Materials Chemistry Group introduced to the chemistry of MCM-41, not least being a method for post-synthetic grafting of aluminium onto this purely silica mesoporous material, leading to an increase in important Brønsted acid groups, ${ }^{40}$ along with retention of chemical properties, overall hexagonal architecture and a remarkable improvement in stability - resistant upon hours of steaming at $750{ }^{\circ} \mathrm{C}$ or extended exposure to boiling water (Figure $5 b) .{ }^{33}$

Another major class of inorganic materials addressed and advanced by the Jones Materials Chemistry Group are LDH solids, composed of cationic mixed-metal hydroxide layers separated by layers of other types of often exchangeable anions. Bill's work on LDHs has included experimental studies on their ion exchange properties, ${ }^{41}$ as well as theoretical investigations ${ }^{42}$ of their structures -especially the possibility of controlling the separation between and arrangement of catalytically active LDH layers through intercalation of inorganic and organic guests. ${ }^{43}$ This is very well illustrated by his development, together with Kooli, ${ }^{44}$ of a simple methodology for intercalation of oxometallate clusters into LDH materials to form pillared structures with permanently open pores. While a detailed description of these contributions and their broader significance remain outside of the scope of this Editorial article, we happily invite the reader to consult the excellent review by Newman and Jones. ${ }^{45}$ Here, however, we would like to highlight the advances that the Jones group has made in the synthesis of LDH materials with intercalated inorganic or organic anions - making the assembly of these materials not only simpler, more efficient, but also "greener"; in other words, more environmentally friendly. ${ }^{46}$ 
The Pfizer Institute for Pharmaceutical Materials Science: contributions to mechanochemistry and pharmaceutical solids

The Materials Chemistry Group has played a pioneering role in the recent emergence of mechanochemical routes for the synthesis of molecules in materials, by providing some of the seminal contributions to using grinding or milling as a methodology to screen for new forms of pharmaceutical solids. Notwithstanding the important contributions of the eminent groups of Toda, ${ }^{47}$ Braga, ${ }^{48}$ Zaworotko $^{49}$ and others ${ }^{50-51}$ to the emergence of mechanochemistry of molecular solids during 1990s and 2000 s, it is not an exaggeration to state that the Jones group was one of the pioneers in the area. In an example of such pioneering work, Bill and coworkers demonstrated in 1996 the use of solvent-free mechanochemistry - in the form of manual grinding using a mortar and a pestle - to synthesize binary and ternary cocrystals. Specifically, the communication "Creation of crystalline supramolecular arrays: a comparison of co-crystal formation from solution and by solid-state grinding" by Pedireddi, Jones, Chorlton and Docherty described an elegant early exploration of how different substituents on a molecule can steer or prevent cocrystallization (Figure 6a,b). ${ }^{52}$

This systematic study provided a blueprint for the later development of strategies in which mechanochemistry is used as a reliable method to explore how elements of molecular structure affect cocrystal formation. A recent example of such a mechanochemistry-based strategy for understanding cocrystallization was reported by Friščić, Trask, Motherwell and Jones, who systematically milled mixtures of caffeine and succinic acid with small molecules of carefully chosen size, shape and polarity, permitting the authors to deduce the importance of $\mathrm{C}-\mathrm{H} \cdots \mathrm{O}$ hydrogen bonds and $\mathrm{Cl} \cdots \mathrm{N}$ or $\mathrm{Br} \cdots \mathrm{N}$ halogen bonds for ternary cocrystallization (Figure $6 \mathrm{c}$ ). ${ }^{53}$

The most significant contributions of the Jones group to modern mechanochemistry were made in the context of pharmaceutical materials, ${ }^{54}$ and eventually established mechanochemistry as ubiquitous in screening for new solid forms of active pharmaceutical ingredients (APIs). The majority of these advances were made by Jones Materials Chemistry Group in the context of the Pfizer Institute for Pharmaceutical Materials Science (PIPMS) during 2000s and 2010s, with Bill as the co-director. Many concepts and techniques that were developed or touched upon by the Jones group during that period became the foundation of modern mechanochemical synthesis and we believe are worth noting in the following sections.

\section{Cocrystals of poorly soluble compounds.}

A major advantage of mechanochemistry over solution- and melt-based cocrystal screening is the ability to avoid bulk liquids and, therefore, the limitations of solubility or thermal sensitivity. Thus, mechanochemistry permits cocrystal screening even with very poorly a)

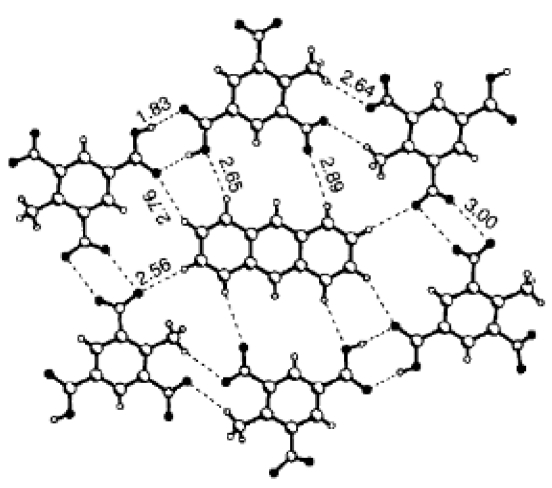

b)

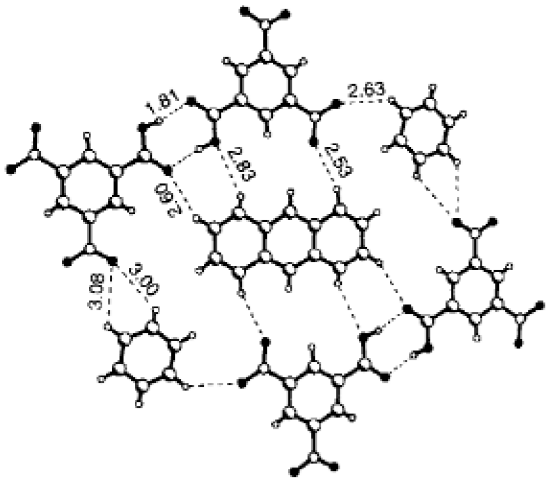

C)

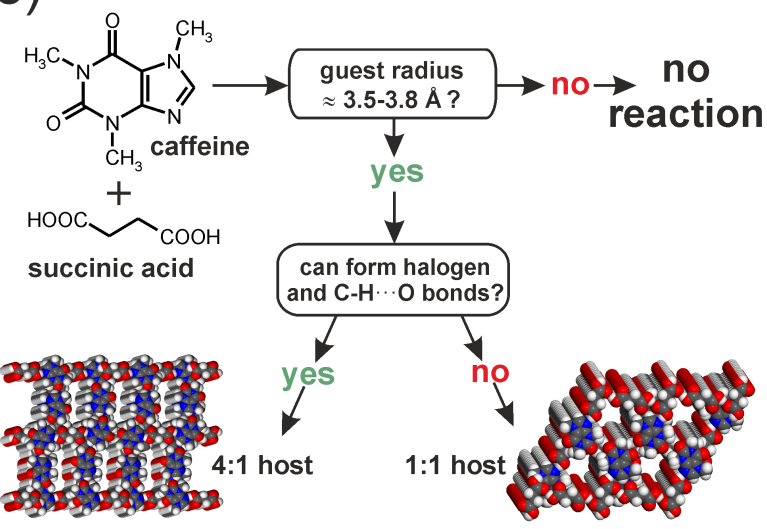

Figure 6. Fragments of crystal structures of mechanochemically obtained: a) binary cocrystal of anthracene with 4methyl-3,5-dinitrobenzoic acid and b) ternary cocrystal of anthracene with 3,5-dinitrobenzoic acid and benzene. c) Relation between molecular structure of a guest molecule and the formation of open hydrogen-bonded host networks of caffeine and succinic acid. Panels (a) and (b) are adapted with permission from reference 52, and panel (c) with permission from reference 53. Copyright 1996 Royal Society of Chemistry and 2008 American Chemical Society.

soluble compounds, ${ }^{55}$ such as APIs. This was illustrated by Karki, who used mechanochemistry to prepare cocrystals of poorly soluble and high-melting theobromine, which were not accessible from solution. ${ }^{56}$

2. Using and combining advanced experimental and theoretical techniques.

This work also highlighted the potential of PXRD for not only evaluating whether a mechanochemical reaction took place, but also for directly determining the structure 

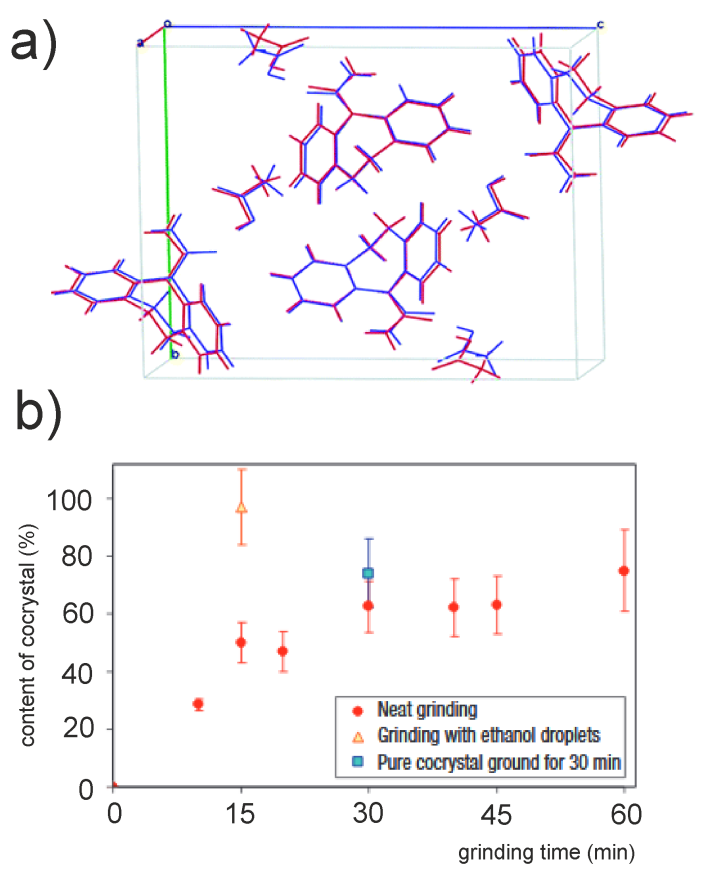

Figure 7. a) Overlay of predicted (red) and experimentally determined (blue) crystal structures for the cocrystal of acetic acid with dihydrocarbamazepine and b) dependence of the amount of cocrystal on milling time and approach, established by THz-TDS in the solid state. Panels (a) and (b) are adapted with permission from refs 57 and 58, respectively. Copyright 2006 American Chemical Society and 2007 Nature Springer.

of the product, sometimes with a bit of assistance of thermal analysis or spectroscopy. This indeed illustrates an important hallmark of Bill's work - the creation of techniques for materials synthesis and using them to challenge new and innovative instrumental and theoretical characterization tools. Such an approach has made the Materials Chemistry Group and PIPMS pioneers in establishing a number of strategies that are still considered cutting-edge in materials science. One of them is using crystal structure prediction (CSP) to direct the experimental search for new materials, elegantly demonstrated when Cruz-Cabeza, Day, Motherwell and Jones first predicted and then experimentally achieved the structure of a previously unknown cocrystal of the API dihydrocarbamazepine (Figure 7a). ${ }^{57}$

Another example is bringing together terahertz timedomain spectroscopy (THz-TDS) and PXRD to establish not only the kinetics of mechanochemical cocrystallization but also to provide rare direct evidence of cocrystal amorphization during milling, as shown by Nguyen, Friščić, Day, Gladden and Jones in 2007 (Figure 7b). ${ }^{58}$ The power of the "Jones-style" integration of theory and experiment is illustrated by a recent tour-de-force study by Arhangelskis, Eddleston, Reid, Day, Bučar, Morris and Jones, ${ }^{59}$ who combined PXRD, electron microscopy, solid-state nuclear magnetic resonance, reflectance UVVis spectroscopy and periodic density functional theory (DFT) modelling to provide a detailed understanding of how the crystal and surface structures of a material dictate the color of a solid organic dye. Other fine examples that illustrate the usefulness of combined theoretical and experimental solid-state research include work on fluorescence by Yan and co-workers in the Jones group, ${ }^{60}$ where halogen bonding with a judiciously chosen fluorescent building block led to new materials with modified optical properties; or the preparation of paracetamol cocrystals wherein flat molecules were built into to enhance the compaction behaviour of the API. ${ }^{61}$

We have no doubt that Bill's multi-disciplinary approach to addressing complexities of solid-state reactivity has also ploughed the way forward for emergent complex and sophisticated methods for real-time monitoring and structural characterization of solid-state reactions.

\section{Making cocrystals that are not accessible from solution.}

An early, simple but striking illustration how mechanochemistry can yield products that are difficult (or even impossible!) to access via solution has been provided by Trask, van de Streek, Motherwell and Jones, who found two distinct cocrystals of caffeine and acetic acid by milling the two in different stoichiometric ratio. ${ }^{62}$ Milling caffeine with acetic acid in a 2:1 stoichiometric ratio led to a cocrystal with identical composition, while milling of a mixture containing equal amounts of the two components gave a cocrystal containing the two in a $1: 1$ ratio (Figure 8). This stoichiometric control of reaction product contrasted solution screening experiments, which always yielded the cocrystal of acetic acid and caffeine in a 2:1 ratio. Such excellent control of reaction stoichiometry using mechanochemistry has since been established in many other mechanochemical processes, from making coordination polymers to organic molecules. $^{63}$

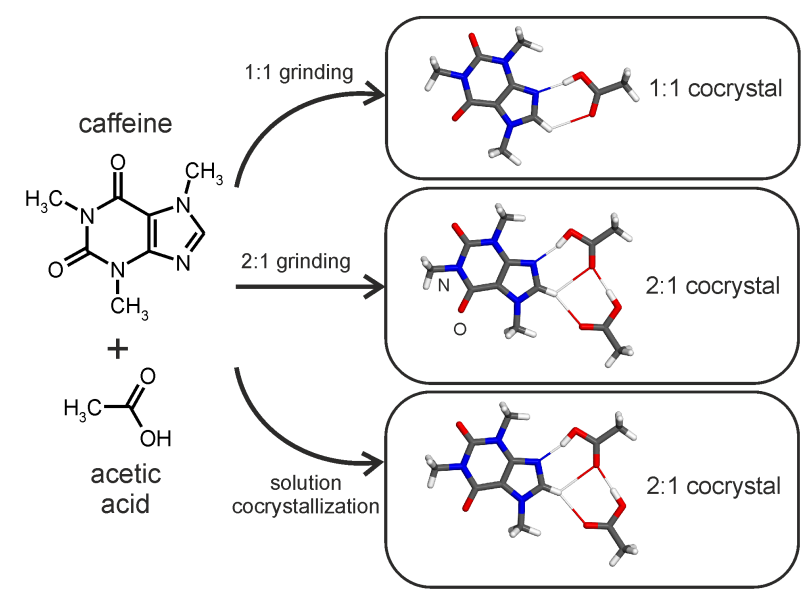

Figure 8. Difference in stoichiometric control in: a) mechanochemical and b) solution-based cocrystallization of caffeine with acetic acid. Mechanochemistry can selectively produce cocrystals with either 1:1 or a 2:1 stoichiometric ratio of acetic acid and caffeine, while solution growth produced only the 2:1 stoichiometry cocrystal. 


\section{Modified mechanochemical methods}

The Cambridge Materials Chemistry group was an early adopter of automated electrical ball milling in investigations of mechanochemical processes (with the pioneering work most certainly been done by the Etter group), ${ }^{64}$ and we believe they must bear significant responsibility for the use of caffeine, theophylline and theobromine as model APIs in cocrystallization studies and, therefore, for the subsequent spike in crystallographic studies of materials containing these molecules. However, perhaps the most important contribution of the Materials Chemistry Group to modern mechanochemistry was the simple discovery that minuscule amounts, sometimes only a drop or two, of a liquid phase can vastly accelerate cocrystallization. For example, addition of 50 microliters (so, around 1-2 drops) of a liquid can reduce time needed for quantitative cocrystallization from hours to minutes, as shown by the seminal paper of Shan, Toda and Jones in 2002. ${ }^{65}$ Even more surprisingly, miniscule amounts of a liquid can even enable cocrystallization of substances that apparently did not yield a cocrystal when milled under dry conditions. This discovery was in many ways critical for the ongoing explosion interest of chemists and materials scientists in mechanochemistry, as "solvent-drop grinding" unexpectedly handed to solid-state chemists a superb method to control and optimize chemical reactions. Systematic studies of this "solvent drop effect" revealed that solubility of solid reactants is now a critical factor for the success of liquid-assisted mechanochemical cocrystallization. Indeed, Bill's team has shown that, in some cases, mechanochemical cocrystallization was equally well promoted by liquids in which solid reactants were respectably soluble, and by liquids in which one or both cocrystallization partners are practically insoluble. ${ }^{66}$ Consequently, solvent-drop grinding was redefined into "liquid-assisted grinding" or (now widely referred to as "LAG ${ }^{667}$ ) and studies in Bill's laboratory led to the introduction of $\eta-$ a parameter to quantitively define LAG, compare it to, as well as distinguish it from other liquid-assisted transformations, such as slurring or solution cocrystallization. ${ }^{66}$ By developing LAG, the Jones group has also shown the way forward for mechanochemistry, by inspiring the development of further modified techniques, where different types of additives enable increasingly powerful means to control and direct reactivity (Figure 8): polymer-assisted grinding (POLAG) ${ }^{68}$ by Hasa and Jones, seeding-assisted grinding by Cinčić and coworkers ${ }^{69}$ and by Bučar and Jones, ${ }^{70}$ or by vapor-assisted grinding by Yuan. ${ }^{71}$

\section{Directing polymorphism through mechanochemistry.}

Besides catalyzing mechanochemical cocrystallization, Bill's group has also established that a liquid additive can direct polymorphism of organic solids. In the first example of this effect, Trask, Shan, Motherwell, Jones, Feng, Tan and Carpenter have shown how solid anthranilic acid can easily be cycled between known a)
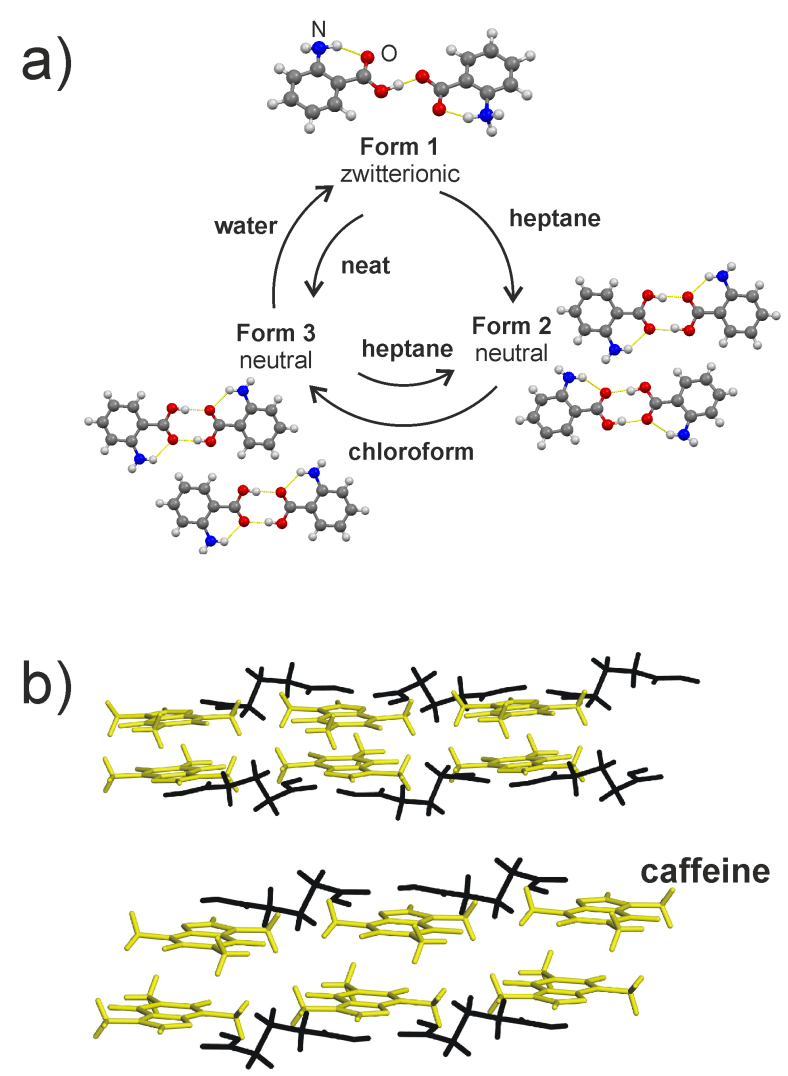

glutaric acid

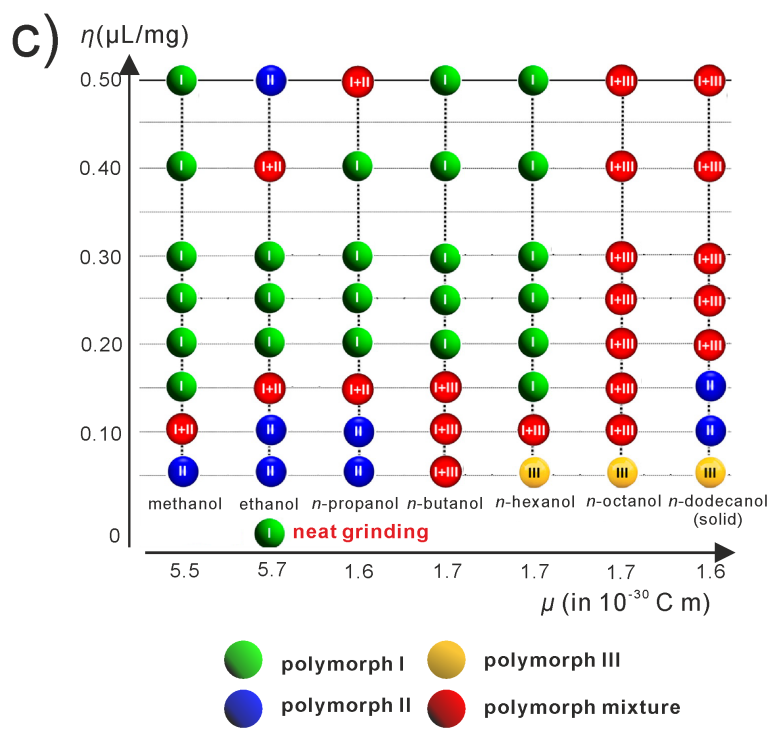

Figure 9. a) Control over polymorphism of solid anthranilic acid by LAG and neat grinding; b) fragments of crystal structures of two polymorphs of the cocrystal of caffeine and glutaric acid, each accessible selectively by LAG with a liquid of a chosen polarity and c) systematic investigation of how $\eta$ and the dielectric constant of the liquid additive affect polymorphism control via LAG of anthranilic acid. Panel (c) is adapted with permission from ref 72. Copyright 2016 American Chemical Society.

polymorphic forms by milling with selected liquid additives (Figure 9a). ${ }^{73}$ This unexpected, simple approach to control polymorphism has also been embraced by other 
groups, and was applicable to cocrystals: for example Trask, Motherwell and Jones have used LAG to selectively make either the form I or form II polymorph of a cocrystal based on glutaric acid and caffeine, with the reaction outcome depending on polarity of the liquid (Figure $9 \mathrm{~b}){ }^{74}$ The high complexity of LAG has been most recently highlighted in a systematic investigation by Hasa, Miniussi and Jones, revealing that polymorphs selection depends not only on the polarity of the liquid, but also the $\eta$-parameter (Figure 9c). ${ }^{72}$

\section{Conclusion}

It is difficult, if not truly impossible, to highlight all exciting, innovative and charming contributions that Bill Jones and his Materials Chemistry Group in Cambridge have provided to understanding and engineering solid materials. No matter how much we tried, we always unraveled more. For this reason, we apologize for omitting the descriptions of truly ingenious work that was conducted in the area of amorphous organic materials, such as trehalose, ${ }^{75}$ and not dedicating more space to outstanding advances that the Jones group as made in CSP in the $21^{\text {st }}$ century. We feel we have also not sufficiently clearly shown how the work of the Jones group has in many ways anticipated the current trends in materials science, for example combining mechanochemistry and photochemistry to achieve cleaner organic synthesis. ${ }^{76}$ Rather to highlight all research contributions, we feel it is also important to note how much Bill Jones has been central to all these successes of the group. Defining his approach to research is not a focus on high-impact journal and high-volume production. Instead, his trademarks have always been an emphasis on understanding, deep thinking and search for the truly important questions. Many of his queries have since become cuttingedge concepts or new products. The very recent emergence of cryo-EM mirocrystal diffraction, ${ }^{77}$ for example, is a stunning development that can also be traced to the type of pioneering work performed by Bill (on pyrene polymorphs reflected on herein $\left.{ }^{1}\right)$ and others.

It is remarkable how much time Bill was able to put aside for discussing research problems and plans with undergraduate and graduate students, postdocs and other team members - even when he took the highly demanding role as the Head of Department at Cambridge. He has always been a true example of modesty and selflessness, in face of his outstanding reputation, which also made him a superb team builder. This was more than obvious at the celebration held in his honor at the University of Cambridge in September of 2017, which brought together many generations of the Jones Materials Chemistry Group as a single family with members of different backgrounds from all continents but Antarctica. With this article, we have attempted to provide an insight into research contributions of Bill Jones, but we must end by highlighting him as a mentor, advisor, leader, supporter and friend to all his groupies.

\section{AUTHOR INFORMATION}

\section{Corresponding Author}

*Email: d.bucar@ucl.ac.uk, tomislav.friscic@mcgill.ca

\section{ACKNOWLEDGMENT}

We thank Bill Jones and all contributors to this Virtual Special Issue for their help and support. We are also immensely grateful to Robin and Mihaela Rogers for their endless patience while we prepared this text.

\section{REFERENCES}

(1) Jones, W.; Ramdas, S.; Thomas, J. M. Novel Approach to the Determination of the Crystal Structures of Organic Molecular Crystals: Low Temperature Form of Pyrene. Chem. Phys. Lett. 1978, $54,490-493$.

(2) Eddleston, M. D.; Hejczyk, K. E.; Cassidy, A. M. C.; Thompson, H. P. G.; Day, G. M.; Jones, W. Highly Unusual Triangular Crystals of Theophylline: The Influence of Solvent on the Growth Rates of Polar Crystal Faces. Cryst. Growth Des. 2015, 15, 2514-2523.

(3) Eddleston, M. D.; Patel, B.; Day, G. M.; Jones, W. Cocrystallization by Freeze-Drying: Preparation of Novel Multicomponent Crystal Forms. Cryst. Growth Des. 2013, 13, 45994606.

(4) Eddleston, M. D.; Hejczyk, K. E.; Bithell, E. G.; Day, G. M.; Jones, W. Polymorph Identification and Crystal Structure Determination by a Combined Crystal Structure Prediction and Transmission Electron Microscopy Approach. Chem. Eur. J 2013, 19, 7874-7882.

(5) Eddleston, M. D.; Hejczyk, K. E.; Bithell, E. G.; Day, G. M.; Jones, W. Determination of the Crystal Structure of a New Polymorph of Theophylline. Chem. Eur. J 2013, 19, 7883-7888.

(6) Chow, E. H. H.; Bučar, D.-K.; Jones, W. New Opportunities in Crystal Engineering - the Role of Atomic Force Microscopy in Studies of Molecular Crystals. Chem. Commun. 2012, 48, 9210-9226.

(7) Thakuria, R.; Eddleston, M. D.; Chow, E. H. H.; Lloyd, G. O.; Aldous, B. J.; Krzyzaniak, J. F.; Bond, A. D.; Jones, W. Use of In Situ Atomic Force Microscopy to Follow Phase Changes at Crystal Surfaces in Real Time. Angew. Chem. Int. Ed. 2013, 52, 1054110544.

(8) Nakanishi, H.; Jones, W.; Thomas John, M.; Hasegawa, M.; Rees, W. L. Topochemically Controlled Solid-State Polymerization. Proceedings of the Royal Society of London. A. Mathematical and Physical Sciences 1980, 369, 307-325.

(9) Cohen, M. D.; Ludmer, Z.; Thomas, J. M.; Williams, J. O.; Lonsdale Kathleen, Y. The Role of Structural Imperfections in the Photodimerization of 9-Cyanoanthracene. Proceedings of the Royal Society of London. A. Mathematical and Physical Sciences 1971, 324, 459-468.

(10) Rees, W. L.; Goringe, M. J.; Jones, W.; Thomas, J. M. Characterization of Dislocations in, and Photoreactivity of, Crystalline 9-Cyanoanthracene. J. Chem. Soc. Faraday Trans. 1979, $75,806-809$.

(11) Jones, W.; Ramdas, S.; Theocharis, C. R.; Thomas, J. M.; Thomas, N. W. Crystal Engineering of Photodimerizable Cyclopentanones. Comparison of Chloro- and Methyl- Substitution as Solid-State Steering Groups. The Journal of Physical Chemistry 1981, $85,2594-2597$.

(12) Jones, W.; Nakanishi, H.; Theocharis, C. R.; Thomas, J. M. Engineering Organic Crystals so as to Control the Photoreactivity of the Reactants and the Crystallinity of the Products. J. Chem. Soc. Chem. Commun. 1980, 610-611.

(13) Nakanishi, H.; Jones, W.; Thomas, J. M.; Hursthouse, M. B.; Motevalli, M. Monitoring the Crystallographic Course of a SingleCrystal $\rightarrow$ Single-Crystal Photodimerization by X-Ray Diffractometry. J. Chem. Soc. Chem. Commun. 1980, 611-612. 
(14) Nakanishi, H.; Jones, W.; Thomas, J. M.; Hursthouse, M. B.; Motevalli, M. Static and Dynamic Single-Crystal X-Ray Diffraction Studies of Some Solid-State Photodimerization Reactions. The Journal of Physical Chemistry 1981, 85, 3636-3642.

(15) Theocharis, C. R.; Nakanishi, H.; Matsuda, H.; Jones, W.; Thomas, J. M.; Kato, M. Structure of a 'Doped' Diacetylene that is Polymerisable in the Solid State. J. Chem. Soc. Chem. Commun. 1985, 1334-1336.

(16) Nakanishi, H.; Matsuda, H.; Kato, M.; Theocharis, C. R.; Jones, W. Single-Crystal Study of the Solid-State Polymerisation of Butadiynylenebis-(m-acetamidobenzene). J. Chem. Soc., Perkin Trans. 2 1986, 1965-1967.

(17) Wang, W.-N.; Jones, W. The Solid State Chemistry of Acridizinium Salts. Tetrahedron 1987, 43, 1273-1279.

(18) Wang, W. N.; Jones, W. The Solid-State Chemistry of Acridizinium and 9-Methylacridizinium Salts. Mol. Cryst. Liq. Cryst. Sci. Technol., Sect. A 1994, 242, 227-240.

(19) Stratford, S. A.; Arhangelskis, M.; Bučar, D.-K.; Jones, W Solid-State Photoreactivity of 9-Substituted Acridizinium Bromide Salts. CrystEngComm 2014, 16, 10830-10836.

(20) Kitaigorodskii, A. I., Applications of Close-Packing Theory to Organic Crystals. In Organic Chemical Crystallography, Consultants Bureau: New York, 1961; pp 113-240.

(21) Theocharis, C. R.; Desiraju, G. R.; Jones, W. The Use of Mixed Crystals for Engineering Organic Solid-State Reactions: Application to Benzylbenzylidenecyclopentanones. J. Am. Chem. Soc. 1984, 106, 3606-3609.

(22) Jones, W.; Theocharis, C. R.; Thomas, J. M.; Desiraju, G. R. Structural Mimicry and the Photoreactivity of Organic Solids. $J$. Chem. Soc. Chem. Commun. 1983, 1443-1444.

(23) Nakanishi, H.; Jones, W.; Parkinson, G. M. 2,5Distyrylpyrazine (DSP)-1,4-bis[2-(2-pyridyl)vinyl]benzene (P2VB) (4:6); A Photopolymerizable Mixed Crystal. Acta Crystallogr. B 1979, 35, 3103-3106.

(24) Edwards, M. R.; Jones, W.; Motherwell, W. D. S.; Shields, G. P. Crystal Engineering and Chloro-Methyl Interchange-a CSD Analysis. Mol. Cryst. Liq. Cryst. Sci. Technol., Sect. A 2001, 356, 337-353.

(25) Edwards, M. R.; Jones, W.; Motherwell, W. D. S Cocrystal Formation of 4-Methyl and 4-Chlorobenzamide with Carboxylic Acids: Chloro/Methyl Interchange and Crystal Structure. CrystEngComm 2006, 8, 545-551.

(26) Desiraju, G. R.; Sarma, J. A. R. P. The Chloro-Methyl Exchange Rule and its Violations in the Packing of Organic Molecular Solids. J. Chem. Sci. 1986, 96, 599-605.

(27) Cinčić, D.; Friščić, T.; Jones, W. Structural Equivalence of $\mathrm{Br}$ and I Halogen Bonds: A Route to Isostructural Materials with Controllable Properties. Chem. Mater. 2008, 20, 6623-6626.

(28) Cinčić, D.; Friščić, T.; Jones, W. Isostructural Materials Achieved by Using Structurally Equivalent Donors and Acceptors in Halogen-Bonded Cocrystals. Chem. Eur. J 2008, 14, 747-753.

(29) Corpinot, M. K.; Guo, R.; Tocher, D. A.; Buanz, A. B. M.; Gaisford, S.; Price, S. L.; Bučar, D.-K. Are Oxygen and Sulfur Atoms Structurally Equivalent in Organic Crystals? Cryst. Growth Des. 2017, 17, 827-833.

(30) Corpinot, M. K.; Bučar, D.-K. A Practical Guide to the Design of Molecular Crystals. Cryst. Gorwth Des. 2018.

(31) Shan, N.; Batchelor, E.; Jones, W. Co-Crystal Structures of 4,7-Phenanthroline and Carboxylic Acids: Synthon Competition and Prediction. Tetrahedron Letters 2002, 43, 8721-8725.

(32) Mokaya, R.; Zhou, W.; Jones, W. A Method for the Synthesis of High Quality Large Crystal MCM-41. Chem. Commun. 1999, 51-52.

(33) Mokaya, R.; Jones, W. Aluminosilicate Mesoporous Molecular Sieves with Enhanced Stability Obtained by Reacting MCM-41 with Aluminium Chlorohydrate. Chem. Commun. 1998, $1839-1840$.

(34) Feeder, N.; Jones, W. N-Saccharinperacetic Acid Monohydrate and N-Saccharinpentanoic Acid Monohydrate. Acta Crystallogr. C 1996, 52, 2323-2326.
(35) Feeder, N.; Jones, W. Comparative Study of Crystal Packing in Amido-Benzoic and Amido-Perbenzoic Acids. Mol. Cryst. Liq. Cryst. Sci. Technol., Sect. A 1994, 240, 231-239.

(36) Kariuki, B. M.; Jones, W. The Chemical and Crystal Changes Accompanying the Thermal Decomposition of HexaAquomagnesium Monoperoxyphthalate. Mol. Cryst. Liq. Cryst. Sci. Technol., Sect. A 1994, 248, 21-34.

(37) Cosgrove, S. D.; Jones, W. The Reversible Desorption of $\mathrm{H} 2 \mathrm{O} 2$ from the Inclusion Channel Complex $4 \mathrm{Na} 2 \mathrm{SO} 4 \cdot \mathrm{NaCl} \cdot 2 \mathrm{H} 2 \mathrm{O} 2$. J. Chem. Soc. Chem. Commun. 1994, 2255-2256.

(38) D. Cosgrove, S.; Jones, W. Chemistry of Sulfate Chloride Perhydrates. Part 2.-Reperhydration by H2O2. J. Mater. Chem. 1998, 8, 419-424.

(39) D. Cosgrove, S.; Jones, W. Chemistry of Sulfate Chloride Perhydrates. J. Mater. Chem. 1998, 8, 1911-1915.

(40) Mokaya, R.; Jones, W. Post-Synthesis Grafting of Al onto MCM-41. Chem. Commun. 1997, 2185-2186.

(41) Newman, S. P.; Jones, W. Comparative Study of Some Layered Hydroxide Salts Containing Exchangeable Interlayer Anions. J. Solid State Chem. 1999, 148, 26-40.

(42) Newman, S. P.; Williams, S. J.; Coveney, P. V.; Jones, W Interlayer Arrangement of Hydrated MgAl Layered Double Hydroxides Containing Guest Terephthalate Anions: Comparison of Simulation and Measurement. J. Phys. Chem. B 1998, 102, 67106719.

(43) Greenwell, H. C.; Jones, W.; Stamires, D. N.; O'Connor, P.; Brady, M. F. A One-Pot Synthesis of Hybrid Organo-Layered Double Hydroxide Catalyst Precursors. Green Chem. 2006, 8, 1067 1072 .

(44) Kooli, F.; Jones, W. Direct Synthesis of PolyoxovanadatePillared Layered Double Hydroxides. Inorg. Chem. 1995, 34, 6237 6238.

(45) P. Newman, S.; Jones, W. Synthesis, Characterization and Applications of Layered Double Hydroxides Containing Organic Guests. New J. Chem. 1998, 22, 105-115.

(46) Greenwell, H. C.; Marsden, C. C.; Jones, W. Synthesis of Organo-Layered Double Hydroxides by an Environmentally Friendly Co-Hydration Route. Green Chem. 2007, 9, 1299-1307.

(47) Toda, F.; Tanaka, K.; Sekikawa, A. Host-Guest Complex Formation by a Solid-Solid Reaction. J. Chem. Soc. Chem. Commun. 1987, 279-280.

(48) Braga, D.; Grepioni, F. Making Crystals from Crystals: a Green Route to Crystal Engineering and Polymorphism. Chem. Commun. 2005, 3635-3645.

(49) Weyna, D. R.; Shattock, T.; Vishweshwar, P.; Zaworotko, M. J. Synthesis and Structural Characterization of Cocrystals and Pharmaceutical Cocrystals: Mechanochemistry vs Slow Evaporation from Solution. Cryst. Growth Des. 2009, 9, 1106-1123.

(50) Friščić, T.; Jones, W. Recent Advances in Understanding the Mechanism of Cocrystal Formation via Grinding. Cryst. Growth Des. 2009, 9, 1621-1637.

(51) Friščić, T. Supramolecular Concepts and New Techniques in Mechanochemistry: Cocrystals, Cages, Rotaxanes, Open MetalOrganic Frameworks. Chem. Soc. Rev. 2012, 41, 3493-3510.

(52) Pedireddi, V. R.; Jones, W.; Chorlton, A. P.; Docherty, R. Creation of Crystalline Supramolecular Arrays: a Comparison of CoCrystal Formation from Solution and by Solid-State Grinding. Chem. Commun. 1996, 987-988.

(53) Friščić, T.; Trask, A. V.; Motherwell, W. D. S.; Jones, W. Guest-Directed Assembly of Caffeine and Succinic Acid into Topologically Different Heteromolecular Host Networks upon Grinding. Cryst. Growth Des. 2008, 8, 1605-1609.

(54) Delori, A.; Friščić, T.; Jones, W. The Role of Mechanochemistry and Supramolecular Design in the Development of Pharmaceutical Materials. CrystEngComm 2012, 14, 2350-2362.

(55) Bučar, D.-K.; Filip, S.; Arhangelskis, M.; Lloyd, G. O.; Jones, W. Advantages of Mechanochemical Cocrystallisation in the Solid-State Chemistry of Pigments: Colour-tuned Fluorescein Cocrystals. CrystEngComm 2013, 15, 6289-6291.

(56) Karki, S.; Fábián, L.; Friščić, T.; Jones, W. Powder X-ray Diffraction as an Emerging Method to Structurally Characterize Organic Solids. Organic Letters 2007, 9, 3133-3136. 
(57) Cruz Cabeza, A. J.; Day, G. M.; Motherwell, W. D. S.; Jones, W. Prediction and Observation of Isostructurality Induced by Solvent Incorporation in Multicomponent Crystals. J. Am. Chem. Soc. 2006, 128, 14466-14467.

(58) Lien Nguyen, K.; Friščić, T.; Day, G. M.; Gladden, L. F.; Jones, W. Terahertz Time-Domain Spectroscopy and the Quantitative Monitoring of Mechanochemical Cocrystal Formation. Nat. Mater. 2007, 6, 206.

(59) Arhangelskis, M.; Eddleston, M. D.; Reid, D. G.; Day, G. M.; Bučar, D.-K.; Morris, A. J.; Jones, W. Rationalization of the Color Properties of Fluorescein in the Solid State: A Combined Computational and Experimental Study. Chem. Eur. J 2016, 22, 10065-10073.

(60) Yan, D.; Delori, A.; Lloyd, G. O.; Friščić, T.; Day, G. M.; Jones, W.; Lu, J.; Wei, M.; Evans, D. G.; Duan, X. A Cocrystal Strategy to Tune the Luminescent Properties of Stilbene-Type Organic Solid-State Materials. Angew. Chem. Int. Ed. 2011, 50 12483-12486

(61) Karki, S.; Friščić, T.; Fábián, L.; Laity, P. R.; Day, G. M.; Jones, W. Improving Mechanical Properties of Crystalline Solids by Cocrystal Formation: New Compressible Forms of Paracetamol. Adv. Mater. 2009, 21, 3905-3909.

(62) Trask, A. V.; van de Streek, J.; Motherwell, W. D. S.; Jones, W. Achieving Polymorphic and Stoichiometric Diversity in Cocrystal Formation: Importance of Solid-State Grinding, Powder Xray Structure Determination, and Seeding. Cryst. Growth Des. 2005, $5,2233-2241$

(63) Štrukil, V.; Margetić, D.; Igrc, M. D.; Eckert-Maksić, M.; Friščić, T. Desymmetrisation of Aromatic Diamines and Synthesis of Non-Symmetrical Thiourea Derivatives by Click-Mechanochemistry. Chem. Commun. 2012, 48, 9705-9707.

(64) Etter, M. C.; Reutzel, S. M.; Choo, C. G. Self-Organization of Adenine and Thymine in the Solid State. J. Am. Chem. Soc. 1993, $115,4411-4412$.

(65) Shan, N.; Toda, F.; Jones, W. Mechanochemistry and CoCrystal Formation: Effect of Solvent on Reaction Kinetics. Chem. Commun. 2002, 2372-2373

(66) Friščić, T.; Childs, S. L.; Rizvi, S. A. A.; Jones, W. The Role of Solvent in Mechanochemical and Sonochemical Cocrystal Formation: A Solubility-Based Approach for Predicting Cocrystallisation Outcome. CrystEngComm 2009, 11, 418-426.

(67) Friščić, T.; Trask, A. V.; Jones, W.; Motherwell, W. D. S. Screening for Inclusion Compounds and Systematic Construction of
Three-Component Solids by Liquid-Assisted Grinding. Angew. Chem. Int. Ed. 2006, 45, 7546-7550.

(68) Hasa, D.; Schneider Rauber, G.; Voinovich, D.; Jones, W. Cocrystal Formation through Mechanochemistry: from Neat and Liquid-Assisted Grinding to Polymer-Assisted Grinding. Angew. Chem. Int. Ed. 2015, 54, 7371-7375.

(69) Cinčić, D.; Brekalo, I.; Kaitner, B. Solvent-Free Polymorphism Control in a Covalent Mechanochemical Reaction. Cryst. Growth Des. 2012, 12, 44-48.

(70) Bučar, D.-K.; Day, G. M.; Halasz, I.; Zhang, G. G. Z.; Sander, J. R. G.; Reid, D. G.; MacGillivray, L. R.; Duer, M. J.; Jones, W. The Curious Case of (Caffeine).(Benzoic Acid): How Heteronuclear Seeding Allowed the Formation of an Elusive Cocrystal. Chem. Sci. 2013, 4, 4417-4425.

(71) Jia, C.; Wang, J.; Feng, X.; Lin, Q.; Yuan, W. Efficient Vapour-Assisted Aging and Liquid-Assisted Grinding Synthesis of a Microporous Copper-Adeninate Framework. CrystEngComm 2014, $16,6552-6555$

(72) Hasa, D.; Miniussi, E.; Jones, W. Mechanochemical Synthesis of Multicomponent Crystals: One Liquid for One Polymorph? A Myth to Dispel. Cryst. Growth Des. 2016, 16, 45824588 .

(73) Trask, A. V.; Shan, N.; Motherwell, W. D. S.; Jones, W.; Feng, S.; Tan, R. B. H.; Carpenter, K. J. Selective Polymorph Transformation via Solvent-Drop Grinding. Chem. Commun. 2005, 880-882.

(74) Trask, A. V.; Motherwell, W. D. S.; Jones, W. SolventDrop Grinding: Green Polymorph Control of Cocrystallisation. Chem. Commun. 2004, 890-891.

(75) Simperler, A.; Kornherr, A.; Chopra, R.; Bonnet, P. A.; Jones, W.; Motherwell, W. D. S.; Zifferer, G. Glass Transition Temperature of Glucose, Sucrose, and Trehalose: An Experimental and in Silico Study. The Journal of Physical Chemistry B 2006, 110, 19678-19684

(76) Shan, N.; Jones, W. A Green Chemistry Approach to the Synthesis of a Crystalline Organic Inclusion Compound. Green Chem. 2003, 5, 728-730.

(77) Jones, C. G.; Martynowycz, M. W.; Hattne, J.; Fulton, T. J.; Stoltz, B. M.; Rodriguez, J. A.; Nelson, H. M.; Gonen, T. The CryoEM Method MicroED as a Powerful Tool for Small Molecule Structure Determination. ACS Cent. Sci. 2018, 4, 1587-1592. 


\title{
Prof. William Jones and his Materials Chemistry Group: Innovations and Advances in the Chemistry of Solids
}

\author{
Dejan-Krešimir Bučar ${ }^{\dagger} *$ and Tomislav Friščić ${ }^{\ddagger} * *$
}

An introduction to the Virtual Special Issue in honor of Prof. William Jones, wherein the authors reflect on his scientific career and his many outstanding contributions to organic-solid-state chemistry.

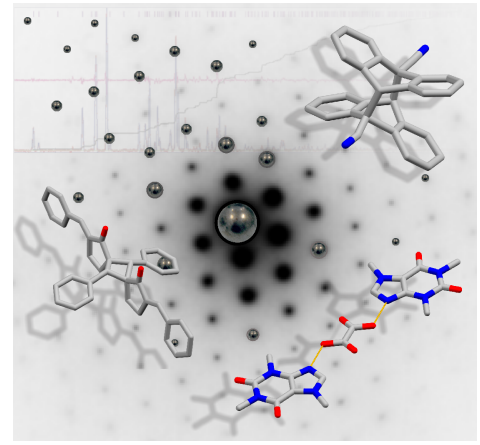

